\title{
Dynamic analysis of different type of wind turbine towers under wind and earthquake effects
}

\author{
Fethi Sermet ${ }^{* 1}$, Muhammet Ensar Yigit ${ }^{(\mathbb{D}}$, Sefa Ergun ${ }^{2}$ (D), Emin Hokelekli3 ${ }^{3}$ \\ ${ }^{1}$ I $\breve{g d}$ r University, Department of Civil Engineering, I $\breve{g} d \imath$, Turkey \\ ${ }^{2}$ Manisa Celal Bayar University, Department of Civil Engineering, Manisa, Turkey \\ ${ }^{3}$ Bartın University, Department of Civil Engineering, Bartın, Turkey
}

\begin{abstract}
Wind energy is one of the most economical and clean energy sources in the world. Investments in wind energy are getting increase. Besides, the construction of huge-sized wind turbine towers can result in high costs. The safety in terms of stress and displacement values are also significant for a selected type of turbine towers along with cost. In the design of a wind turbine, the dynamic loads such as wind and earthquake which influence on the tower are also significant. In this regard, dynamic analyses performed for the selection of a wind turbine tower type enable a convenient optimization. In this research, three different towers which have $10 \mathrm{~m}$ high were designed. These towers with calculated wind forces and, the recorded acceleration data of earthquakes took place in Chi-Chi, Düzce and Kobe were analyzed using ABAQUS software calculating based on finite element method. The results show that the highest tensile and displacement values were obtained from steel tower type. In terms of stress and displacement values, the most suitable tower type was the hybrid tower.
\end{abstract}

\section{Keywords}

Finite element analysis; Wind turbine tower; Dynamic analysis.

Received: 02 October 2019; Accepted: 02 September 2020

ISSN: 2630-5763 (online) (C) 2020 Golden Light Publishing All rights reserved.

\section{Introduction}

Although wind forces are unsteady they are considered as steady in most cases. Moreover, the characteristic of the wind forces are different each other. The types of hurricanes and storm bring about sudden loads which give rise to huge structural problems [1-3]. Therefore, the wind forces must be taken into consideration as a dynamic load. Wind turbines are continuously exposed to dynamic loads. The most significant loads are wind and seismic forces. In the case wind and seismic loads on a tower, the design of the tower that can withstand the loads safely is also a crucial issue [4-6]. Many wind turbine failure is stemming from these loads. Therefore, this system needs to be optimized and studied on its dynamic reliability. Yang et al. (2015) study on dynamic reliability of the tripod sub-structure of offshore wind turbines by taking into account wind loads, wave, seismic wave and turbine forces [7]. Patil et al. (2016) evaluated the structural performance of a typical wind turbine tower subjected to strong ground motions [8].

\footnotetext{
Corresponding author

Email: fethi.sermet@igdir.edu.tr
} 
The structural performance of the wind turbine tower was also investigated through seismic fragility analysis. Quilligan et al. (2012) investigated the performance of the steel and concrete tower using a flapwise numerical model for different tower heights and wind speeds [9]. They suggested that prestressed concrete towers can provide a viable alternative and offer an improved performance. Hsu et al. (2014) carry out reliability analyses of large size wind turbine towers [10]. They used finite element method to investigate its structural responses under static and fatigue loads. They stated that the majority of loads on the tower are the wind forces acting on the rotational area of the wind turbine blades, and the moments resulting from the non-uniform wind speed [11-16].

The current study aims to compare the displacement and stress values of different turbine towers under wind loads and seismic forces recorded from acceleration of Chi-Chi, Düzce and Kobe earthquakes. In this study, finite element model was developed to investigate dynamic behaviour using ABAQUS software [17].

\section{Mathematical model of wind turbine}

The governing equation for a wind turbine tower (Fig. 1) subjected to an earthquake excitation can be given as equation (1-2) [18]. In order to do forced vibration analysis of a tower, the mass, damping, stiffness matrices and equivalent nodal loads vector of the tower should be constructed.

$$
\begin{aligned}
& M \ddot{u}+C \dot{u}+K u=F_{s t c}+F_{d y n} \\
& F_{d y n}=-M \ddot{u}_{g}
\end{aligned}
$$

where $M$ is the mass matrix, $C$ is the damping matrix, $K$ is the stiffness matrix, respectively, $u$, $\dot{u}$ and $\ddot{u}$ are the lateral displacement, lateral velocity of and the lateral acceleration of the tower with respect to time. $F_{s t c}$ is the lateral wind force acting on the turbine, $F_{d y n}$ is the dynamic forces acting on the turbine, $\ddot{u}_{g}$ is the earthquake acceleration.

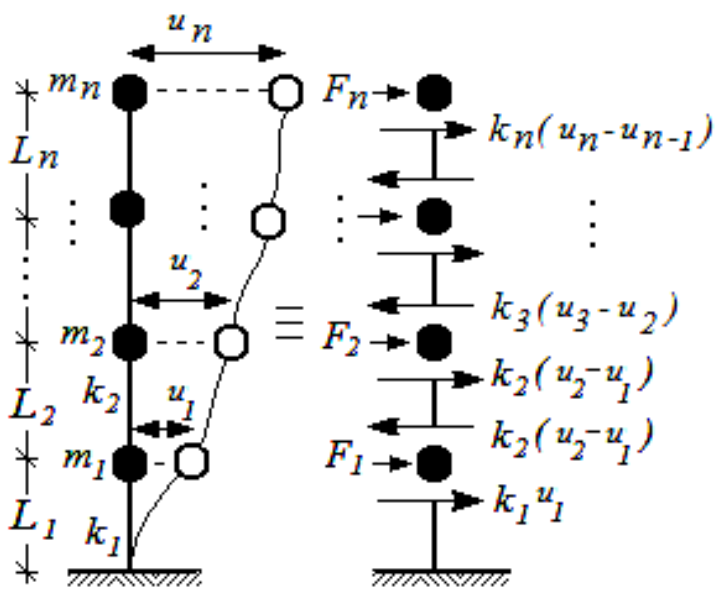

Fig. 1. The multi-degree of freedom system

Analytical solution of wind turbine structures displacements can be calculated by multi degree of freedom (MDOF) system (Fig 1). The calculations of the displacements and stresses of the structure by neglecting the term damping (c) are shown in Eqs. (3) to (15).

\subsection{Calculation of displacements}

Dynamic-equilibrium equations based on D'Alembert Principle can be expressed for each mass. For unforced displacement of system, the equation of motion for each mass can be written as [3]

$$
\begin{aligned}
& F_{1}=m_{1} \ddot{u}_{1} \\
& F_{2}=m_{2} \ddot{u}_{2} \\
& \vdots \\
& F_{N}=m_{n} \ddot{u}_{n} \\
& m_{1} \ddot{u}_{1}+k_{1} u_{1}-k_{2}\left(u_{2}-u_{1}\right)=0 \\
& m_{2} \ddot{u}_{2}+k_{2}\left(u_{2}-u_{1}\right)-k_{3}\left(u_{3}-u_{2}\right)=0 \\
& \vdots \\
& m_{(n)} \ddot{u}_{(n)}+k_{n}\left(u_{n}-u_{(n-1)}\right)=0
\end{aligned}
$$

Here, $m_{l}, m_{2}, \ldots, m_{n}$; mass influence coefficient, $k_{l}$, $k_{2}, \ldots, k_{n}$ stiffness influence coefficients, and $F_{1}, F_{2}, . ., F_{n}$; forces resulting from the motion. However, it is supposed that displacements of motion; $u_{1}, u_{2}, \ldots, u_{n}$ are defined in terms of harmonic excitation response spectrums at the frequency $\omega_{1,2, \ldots, n}$.[3] 


$$
\begin{aligned}
& u_{1}=q_{1} \sin (\omega t) \\
& u_{2}=q_{2} \sin (\omega t) \\
& \vdots \\
& u_{n}=q_{n} \sin (\omega t)
\end{aligned}
$$

In which, $q, \omega$ and $t$ indicate respectively as an amplitude of displacement $(\mathrm{m})$, frequency $(1 / \mathrm{sec})$, and time (sec). The derivatives of displacement functions $\left(u_{1}, u_{2}, \ldots, u_{n}\right)$ representing the displaced shape of the structure can be written as

$$
\begin{array}{r}
-m_{1} \omega^{2} q_{1} \sin (\omega t)+k_{1} q_{1} \sin (\omega t) \\
-k_{2} q_{2} \sin (\omega t)+k_{2} q_{1} \sin (\omega t)=0 \\
-m_{2} \omega^{2} q_{2} \sin (\omega t)+k_{2} q_{2} \sin (\omega t) \\
\quad-k_{3} q_{3} \sin (\omega t)+k_{3} q_{2} \sin (\omega t)=0 \\
\begin{array}{r}
-m_{n} \omega^{2} q_{n} \sin (\omega t)+k_{n} q_{n} \\
\sin (\omega t) \\
-k_{n} q_{n-1} \sin (\omega t)=0
\end{array}
\end{array}
$$

Matrix form resulting from dynamic-equilibrium equations can be expressed as

$$
\begin{gathered}
{\left[\begin{array}{cccc}
k_{1}+k_{2} & -k_{2} & \cdots & 0 \\
-k_{2} & k_{2}+k_{3} & -k_{3} & \vdots \\
\vdots & -k_{3} & \ddots & -k_{n} \\
0 & \cdots & -k_{n} & k_{n}
\end{array}\right]\left[\begin{array}{l}
q_{1} \\
q_{2} \\
\vdots \\
q_{n}
\end{array}\right]} \\
-\omega^{2}\left[\begin{array}{cccc}
m_{1} & 0 & \cdots & 0 \\
0 & m_{2} & \cdots & \vdots \\
\vdots & \vdots & \ddots & 0 \\
0 & \cdots & 0 & m_{n}
\end{array}\right]\left[\begin{array}{l}
q_{1} \\
q_{2} \\
\vdots \\
q_{n}
\end{array}\right]=\left[\begin{array}{l}
0 \\
0 \\
\vdots \\
0
\end{array}\right]
\end{gathered}
$$

In matrix notation

$$
\left([K]-\omega^{2}[M]\right) \vec{q}_{i}=0
$$

Matrix of modal amplitudes becomes below

$$
\varphi=\left[q_{i, j}\right]
$$

In order to derive equation of motion on forced system, the externally applied force $F(t)$ must be added to equation of motion on unforced system

$$
\varphi=\left[q_{i, j}\right]
$$

This can be expressed as in terms of modal matrix $\varphi$ and principal coordinates $\{\eta\}$

$$
\{u\}=[\varphi]\{\eta\}
$$

with coordinate transformation and multiplying by $[\varphi]^{T}$ of each term, the equation of motion is derived as follows

$$
[\varphi]^{T}[M][\varphi]\{\ddot{u}\}+[\varphi]^{T}[K][\varphi]\{u\}=[\varphi]^{T}\{F(t)\}
$$

The forced motion equation in the above matrix form can be solved and the motion of the structure (u) can be obtained. The analytical solution of the equation is well known in the literature $[3,6]$.

\subsection{Calculation of stresses}

Mises stresses in the structure as a result of the forces acting on the tower are calculated by the following relations and their stresses are directly related to the deviatoric components in the energy equation.

$$
W=\frac{1}{2} \sigma: \varepsilon
$$

The following expression known in Hooke's Law is written in the equation,

$\varepsilon=\frac{1}{2 G} \sigma$

the energy equation is independent of displacements. Here, $W$ is the strain energy density, $G$ is the shear modulus, $\sigma$ is the stress, $\varepsilon$ is the unit deformation.

Von Mises Stress equation is obtained by writing the energy equation in terms of stresses $[19,20]$ as

$$
\sigma_{V M}=\sqrt{\frac{3}{2} \sigma_{i j} \sigma_{i j}-\frac{1}{2}\left(\sigma_{k k}\right)^{2}}
$$

In this study, the oscillation of the structure under the influence of static and dynamic loads is modeled and solved. The models are difficult to solve analytically. Therefore, they are analyzed by using finite element program. The analysis results of the models are compare to each other. 


\section{Design of an industrial wind turbine towers}

In this section; steel, hybrid (reinforced concrete and steel) and reinforced concrete wind turbine towers with a cylindrical form, having a diameter $(D)$ of $45 \mathrm{~cm}$ and a high $(L)$ of $10 \mathrm{~m}$, are designed. The thickness of steel tower is $5 \mathrm{~mm}$. The steel type is S-355. The compressive strength and a density of the concrete mixture were $35 \mathrm{MPa}$ and $2400 \mathrm{~kg} / \mathrm{m} 3$ respectively and the ratio of poisson of concrete is 0.3 . The reason of the selected design parameters is because costs are very close to each other $[21,22]$. The analysis of the wind turbine towers was performed using ABAQUS software [17]. The deformations and stress that occur in the wind turbine towers were, then, examined.

The reason to choose the industrial wind turbine tower is due to large demand of smaller power plants. Because, smaller power plants are enough to provide energy necessary to be use small towns or establishment. The greatest advantage of this type of production is that it is realized at the moment of consumption, the transmission and storage losses are almost reduced to zero. The details of the designs of the towers are given in Fig. 2.

\subsection{Finite element model}

Finite element analyzes of three different types of wind towers were made using the ABAQUS program. Due to the small dimensions of the wind turbines considered, the dynamic effects caused by the blades were neglected and only the wind force affecting the tower was taken into account. Rotor and blade weights are affected as a mass from the peak.

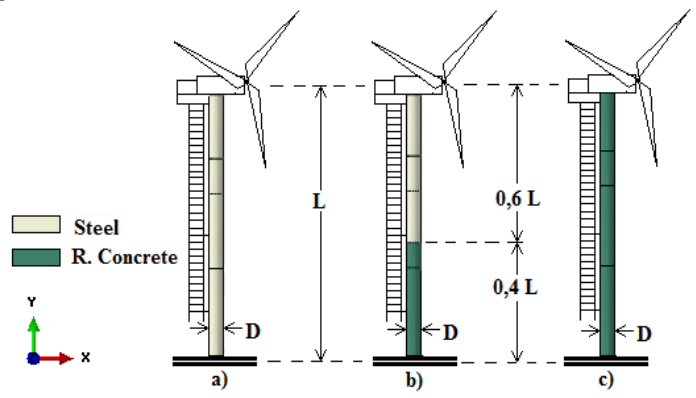

Fig. 2. The section and model of the columns of (a) Steel, (b) Hybrid and (c) Reinforced Concrete tower
The steel tower was modeled using 4-node shell element (sr4), concrete material 8-node solid element (C3D8), reinforcement 2-dimensional bar element 2D trus elements. The tower parts were connected to each other in geometry using a merge process. The reinforcements were embedded in the concrete. The steel tower is designed using tetrahedron (4 corners) and concrete tower hexahedron (6 corners) mesh models. For modeling the turbine tower, $335 \mathrm{MPa}$ yield stress and modulus of elasticity $200 \mathrm{GPa}$ was used. The density of the steel is assumed to be $7850 \mathrm{~kg} / \mathrm{m}^{3}$. The material properties of the steel are listed in Table 1.

\section{Dynamic analysis}

Wind turbine towers are randomly subjected to wind and seismic loads. Due to the high tower supported with structures, it requires sufficient bending stiffness to avoid large deformation under transverse load and to achieve the minimum natural frequency [7].

\subsection{Time-history analysis}

Different methods are used for earthquake resistant structures designs. One of the most up-to-date methods is nonlinear analysis in the Time-history. When performing seismic analysis with this method, acceleration records of earthquakes that have occurred before are used. These earthquake acceleration records are obtained from different sources with very different methods. These are: Design acceleration spectrum compatible artificial records, simulation records and records recorded during the earthquake [29]. In this study, three different earthquake acceleration records recorded during the earthquake were used. Linear inelastic behavior of single degree of freedom system was compared using these records.

Table 1. Properties of steel (S-355) used for material modeling.

\begin{tabular}{cccc}
\hline $\begin{array}{c}\text { Yield } \\
\text { stress } \\
{[\mathrm{MPa}]}\end{array}$ & $\begin{array}{c}\text { Ultimate } \\
\text { stress } \\
{[\mathrm{MPa}]}\end{array}$ & $\begin{array}{c}\text { Young's } \\
\text { Modulus } \\
{[\mathrm{GPa}]}\end{array}$ & $\begin{array}{c}\text { Poisson's } \\
\text { ratio }\end{array}$ \\
\hline 355 & 510 & 200 & 0.3 \\
\hline
\end{tabular}




\section{Load conditions}

Loads applied to wind turbine towers are estimated according to the calculation methods of TIA/EIA222-F code. The loads are given in Table 2 [23-26]. These loads were applied to the same points in the each model and then, analyzed in the same way in this study. The records from Duzce, Chi-Chi, and Kobe earthquakes were considered as earthquake loads (Fig. 3).

\subsection{Wind force}

The horizontal force $(F)$ applied to each section of the structure shall be calculated by

$$
F=q_{z}+G_{H}\left[C_{F} A_{E}+C_{A}+A_{A}\right](N)<2 q_{z} G_{H} A_{G}(N)
$$

where, $\mathrm{A}_{A}$ is the projected area of a linear appurtenance, $A_{C}$ is the projected area of a discrete appurtenance, $A_{G}$ is the gross area of one tower face as if the face were solid, $A_{E}$ is the effective projected area of structural components in one face, $C_{A}$ is the linear or discrete appurtenance force coefficient, $C_{F}$ is the structure force coefficient, $G_{H}$ is the gust response factor for fastest-mile basic wind speed, $D p$ is the average diameter or average least width of a tubular pole structure and $q_{z}$ is the velocity pressure.

The velocity pressure $\left(q_{z}\right)$ and the exposure coefficient $\left(\mathrm{K}_{\mathrm{z}}\right)$ shall be calculated from the equations 18 :

$q_{z}=0.613 \times K_{z} V^{2}$

$$
K_{z}=[z / 10]^{2 / 7} \text { and } 11 \leq K_{z} \leq 2.58
$$

For tubular pole structures, the gust response factor $\left(\mathrm{G}_{\mathrm{H}}\right)$ shall be 1.69 according to TIA/EIA222-F standards.
Structure Force Coefficient (CF) (TIA/EIA222-F)

$$
C_{F}=\sqrt{K_{z} \cdot V \cdot D_{p}}
$$

Here, $F_{C}$ is a design wind load on a discrete appurtenance calculated by

$$
F_{C}=q_{z} G_{H}\left[\sum C_{A} A_{C}\right]
$$

\subsection{Turbine weight}

The turbine weight for the $10 \mathrm{~m}$ high wind turbine was calculated from Eq. (20) as

Turbine weight $=m_{\text {rotor }}+m_{\text {flange }}+m_{\text {shell }}=456.16 \mathrm{~N}$

\subsection{Ice load}

Wind turbines operating in cold climate are sensitive to icing events. $2 \mathrm{~cm}$ thick ice added to all sections has created an ice weight that will affect the system on the y axis apart from the weight of the tower itself. The ice weight formed on each tower piece was calculated. Ice loads are individually activated to the system from the center of gravity of the tower parts.

Table 2. Loads of wind turbine tower [23,28]

\begin{tabular}{ccc}
\hline \multirow{2}{*}{$\begin{array}{c}\text { Load } \\
\text { Direction }\end{array}$} & \multicolumn{2}{c}{ TIA/EIA-222-F } \\
\cline { 2 - 3 } & Load Type & Load \\
\hline$x-x$ & $\begin{array}{c}\text { Wind Load } \\
\text { (Turbine) }\end{array}$ & $12890.81 \mathrm{~N}$ \\
$y-y$ & Turbine Weight & $456.16 \mathrm{~N}$ \\
$z-z$ & Ice Load (Tower) & $2302.6 \mathrm{~N}$ \\
$x-x$ & Wind Load & $2909.64 \mathrm{~N} / \mathrm{m}$ \\
\hline
\end{tabular}

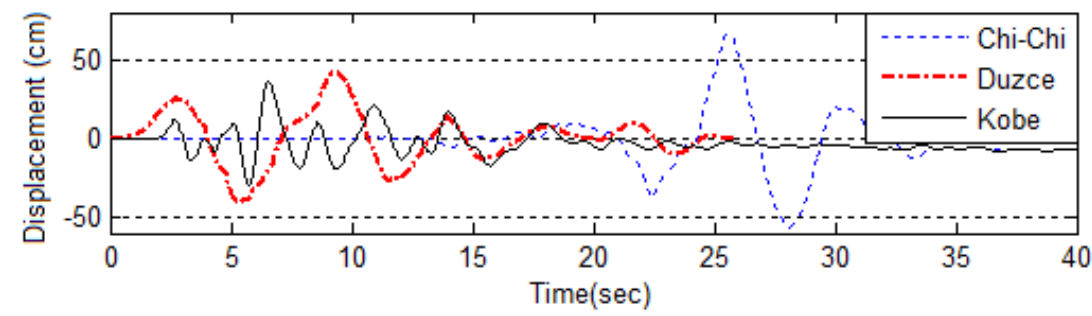

Fig. 3. Displacement-time curves of different earthquakes 
As seen in Fig. 4, the forces acting on the structure include the wind and earthquake loads on the tower, the turbine weight on the tower top.

The load distributions on the deformed models of the towers made of Steel, Hybrid and Reinforced Concrete towers are shown in Fig. 4.

\section{Results}

The maximum displacements for steel, hybrid and reinforced concrete towers are shown in Table 3. The largest displacements are shown in red contour region. According to the displacement contours, the maximum displacement at the top of the tower is 0.889 m (Figs. 5-10).

The maximum displacements of end points on the towers which are reinforced concrete, hybrid and steel, under Chi-Chi, Düzce and Kobe earthquakes are illustrated in Figs. 5-7. As seen in these figures, maximum displacement is obtained as $0.889 \mathrm{~m}$ at $\mathrm{Chi}$ - chi earthquake when using steel tower while the minimum displacement is $0.477 \mathrm{~m}$ under Kobe earthquake for hybrid tower. In general, the maximum displacement occurred at Chi-chi for three type towers. Duzce earthquake results in an average value of the displacement of Chi-Chi and Kobe earthquakes. Besides, a minimum displacement was obtained under Kobe earthquake for each type of tower.
When examining the displacement-time records of the earthquakes, given in Fig. 3, maximum ground motion is seen as $0.669 \mathrm{~m}$ in Chi-Chi earthquake, $0.421 \mathrm{~m}$ in Düzce earthquake and 0.357 $\mathrm{m}$ in Kobe earthquake. Relative horizontal displacements between the top and bottom points of the towers are given in Table 4. Relative horizontal displacements were found by subtracting earthquakes from absolute displacements of the tower endpoint. The absolute displacements of the top points of the towers under the earthquake loads are shown in Table 3 and Figs. 4-9.

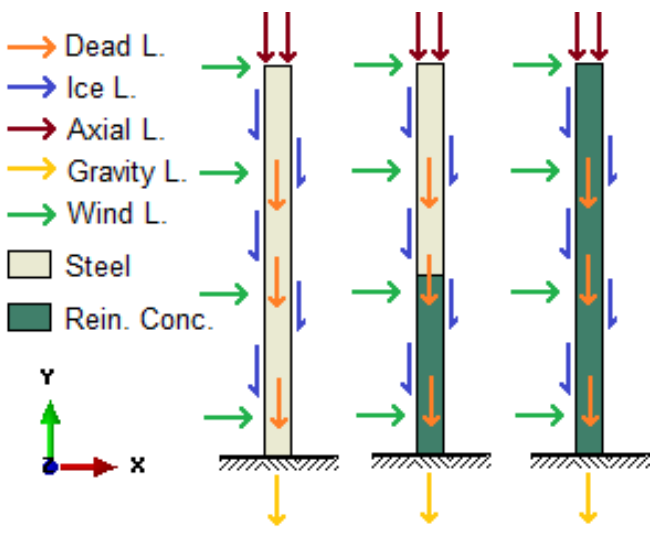
a)
b)
c)

Fig. 4. Load distributions of (a) Steel, (b) Hybrid and (c) Reinforced Concrete tower

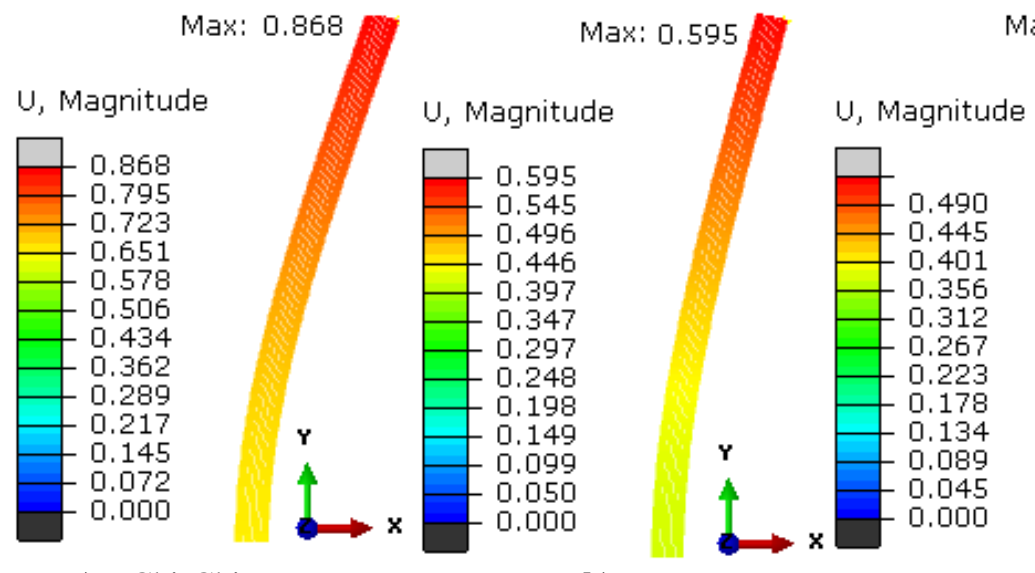

a) Chi-Chi

b) Düzce

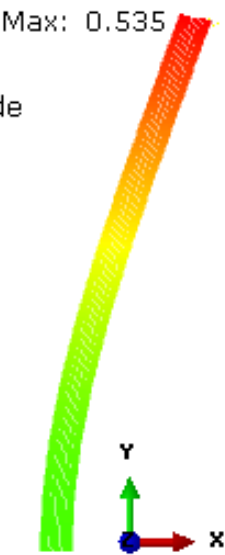

c) Kobe

Fig. 5. Max. displacements for the reinforced concrete tower under the different earthquake loads $(U(m))$. 


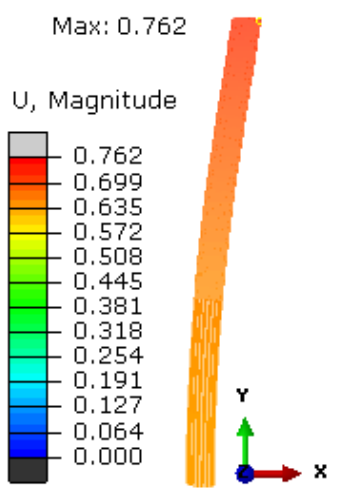

a) Chi-Chi

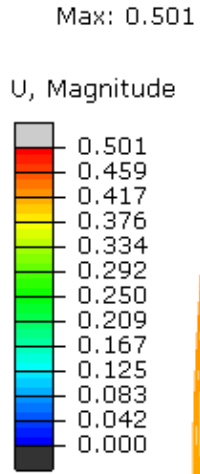

b) Düzce

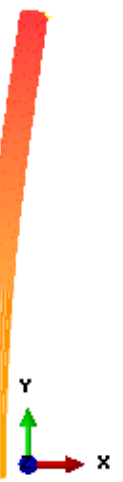

$x$

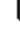

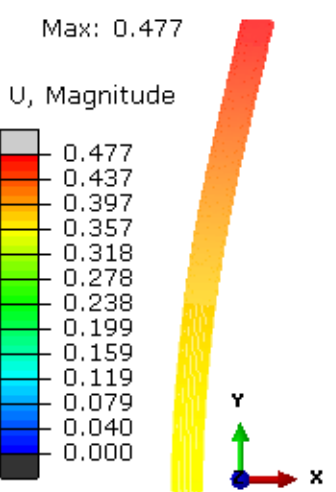

c) Kobe

Fig. 6. Max. displacements for the hybrid tower under the different earthquake loads (U (m)).

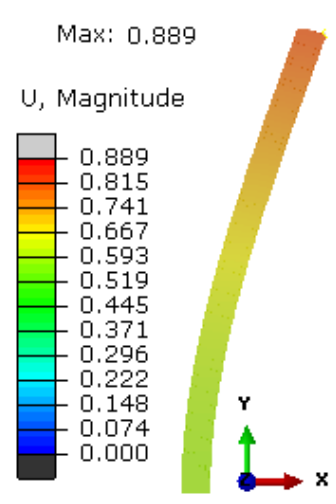

a) Chi-Chi

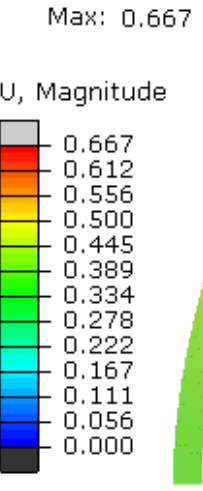

b) Düzce

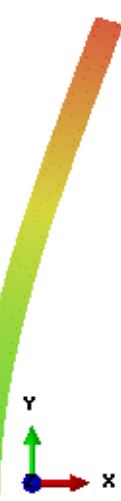

$x$

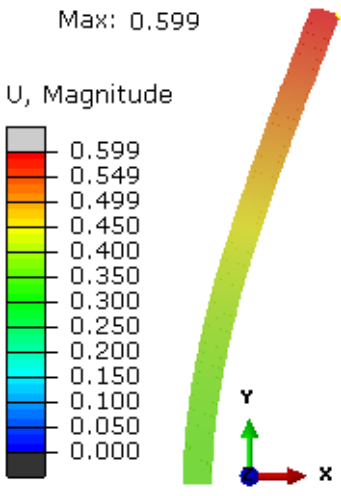

c) Kobe

Fig. 7. Max. displacements for the steel tower under the different earthquake loads $(U(m))$.

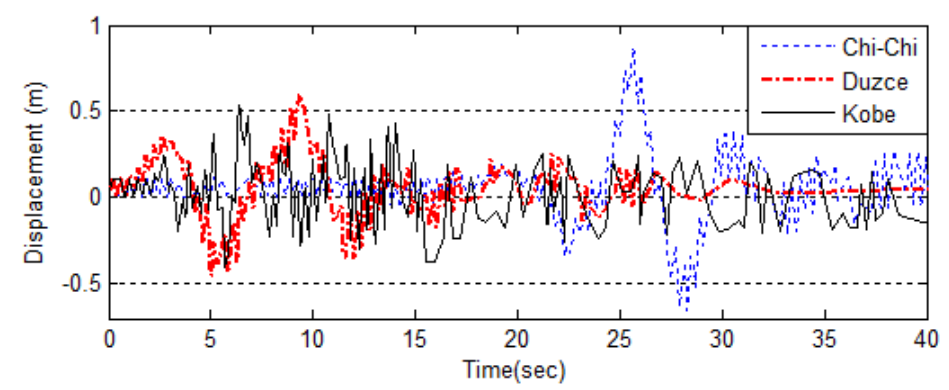

Fig. 8. Displacement-time curves for the reinforced concrete tower under the different earthquake loads

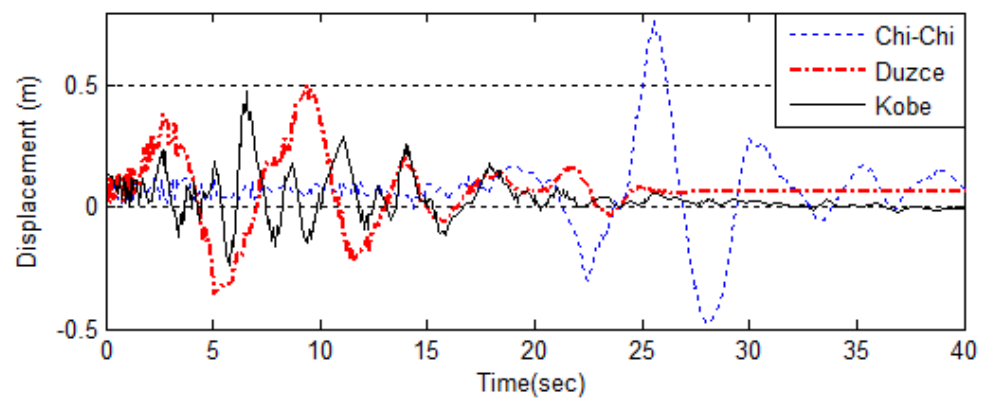

Fig. 9. Displacement-time curves for the hybrid tower under the different earthquake loads 


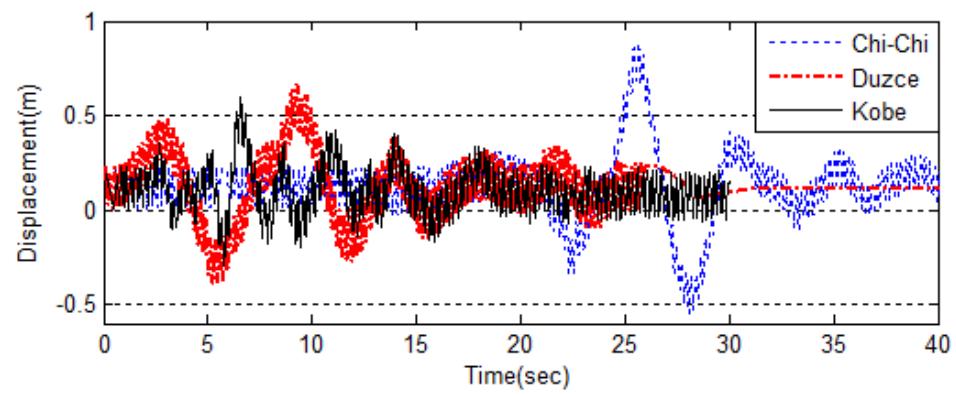

Fig. 10. Displacement-time curves for the steel tower under the different earthquake loads

Table 3. Max displacement and stress on towers

\begin{tabular}{lcccc}
\hline \multicolumn{1}{c}{ Loads/Tower } & $\begin{array}{c}\text { Steel } \\
\text { Tower }\end{array}$ & $\begin{array}{c}\text { Hybrid } \\
\text { Tower }\end{array}$ & RC Tower \\
\hline \multirow{3}{*}{ Maximum } & Under Static Loads & 0.058 & 0.067 & 0.120 \\
Displacement (m) & Chi-Chi & 0.889 & 0.762 & 0.868 \\
& Düzce & 0.667 & 0.501 & 0.595 \\
& Kobe & 0.599 & 0.477 & 0.535 \\
Stress (MPa) & Under Static Loads & 168.203 & 94.711 & 72.029 \\
& Chi-Chi & 313.154 & 127.384 & 282.156 \\
& Düzce & 333.062 & 159.351 & 215.816 \\
& Kobe & 339.093 & 157.193 & 440.415 \\
\hline
\end{tabular}

Table 4. Max relative displacement on towers

\begin{tabular}{lccccc}
\hline & Loads/Tower & $\begin{array}{c}\text { Earthquake } \\
\text { Displacement }\end{array}$ & $\begin{array}{c}\text { Steel } \\
\text { Tower }\end{array}$ & $\begin{array}{c}\text { Hybrid } \\
\text { Tower }\end{array}$ & RC Tower \\
\hline Maximum & Under Static Loads & 0 & 0.058 & 0.067 & 0.120 \\
Relative & Chi-Chi & 0.669 & 0.220 & 0.093 & 0.199 \\
Displacement & Düzce & 0.421 & 0.246 & 0.102 & 0.174 \\
(m) & Kobe & 0.357 & 0.242 & 0.120 & 0.178 \\
\hline
\end{tabular}

As seen in Tables 3-4, the max displacement of the steel tower is occurring by Chi-Chi earthquake while the relative maximum displacement occurs at Duzce earthquake. This situation explains the occurrence of the maximum stress in the steel tower by earthquake. In the hybrid tower, max absolute displacement occurs with Chi-Chi earthquake. Maximum relative displacement occurred in the earthquake of Kobe, and the maximum stresses of hybrid tower were greater than Kobe earthquake due to the resultant of this displacements.

In the case the concrete tower, both the maximum absolute and relative displacements occurred in the Chi-Chi earthquake. Unlike other towers, the max stress formed in the Kobe earthquake. This is due to the fact that the oscillation period of Kobe earthquake acting as shown in Fig. 3 to the reinforced concrete tower was shorter than half of the Chi-Chi and the periods of Duzce earthquake caused more seismic force in the reinforced concrete tower that has bigger a weight than others.

Figs. 11-13 show the stress of each tower subjected to Chi-Chi, Düzce and Kobe earthquakes. When comparing the values of the stress, the maximum value, about $440 \mathrm{GPa}$, was obtained at the reinforced concrete tower and Kobe earthquake. On the other hand, the minimum stress was obtained as about $127 \mathrm{GPa}$ at the hybrid tower and Chi-Chi earthquake. These displacement values depending on time are given in Figs. 14-16. 


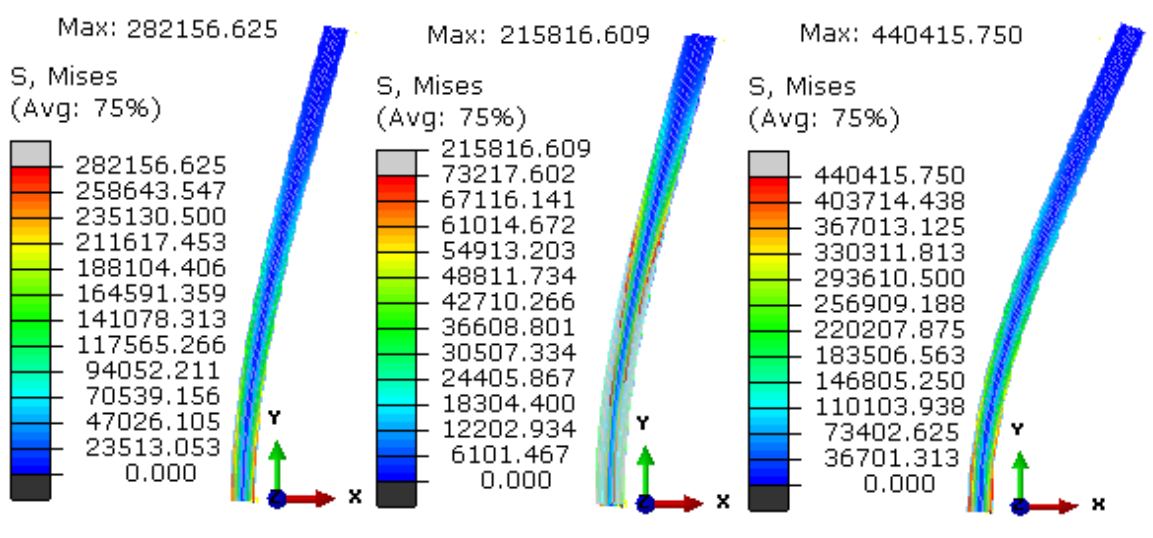
a) Chi-Chi
b) Düzce
c) Kobe

Fig. 11. Max. stress for the reinforced concrete tower under the different earthquake loads (S (MPa)).

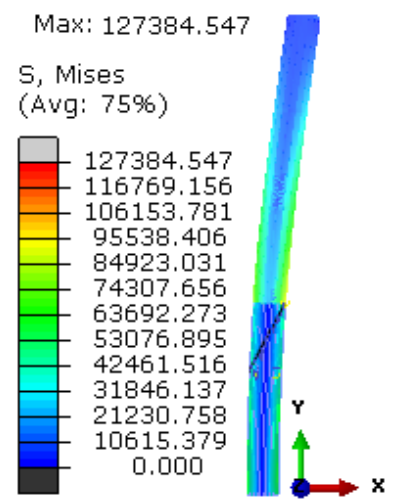

a) Chi-Chi

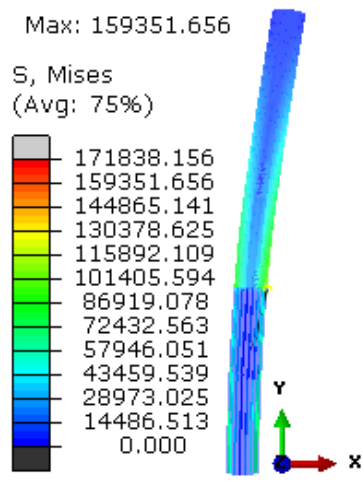

b) Düzce
Max: 174343.625

$\mathrm{S}$, Mises

(Avg: 75\%)

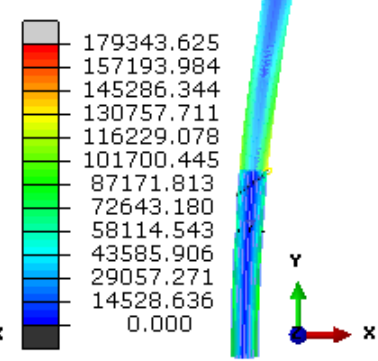

c) Kobe

Fig. 12. Max. stress for the hybrid tower under the different earthquake loads (S (MPa)).

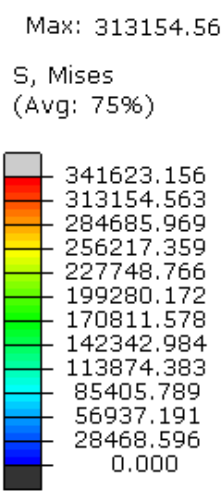

a) Chi-Chi
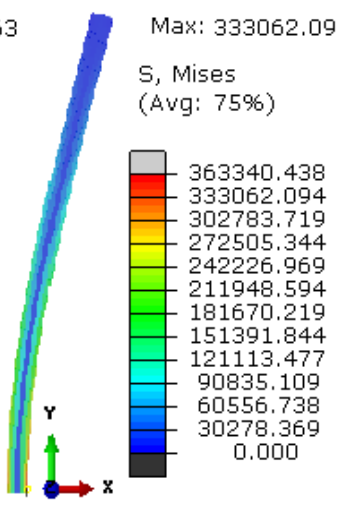

b) Düzce
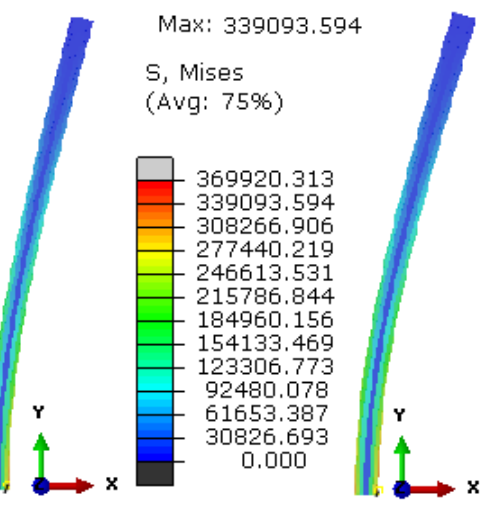

c) Kobe

Fig. 13. Max. stress for the steel tower under the different earthquake loads (S (MPa)). 


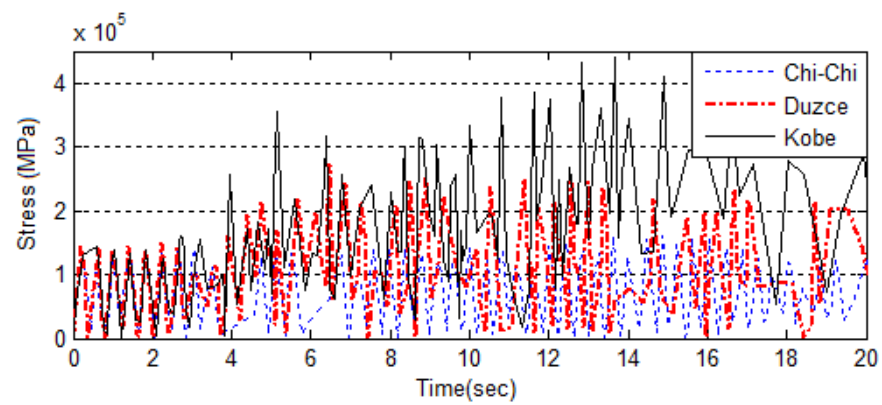

Fig. 14. Stress-time curves for the reinforced concrete tower under the different earthquake loads

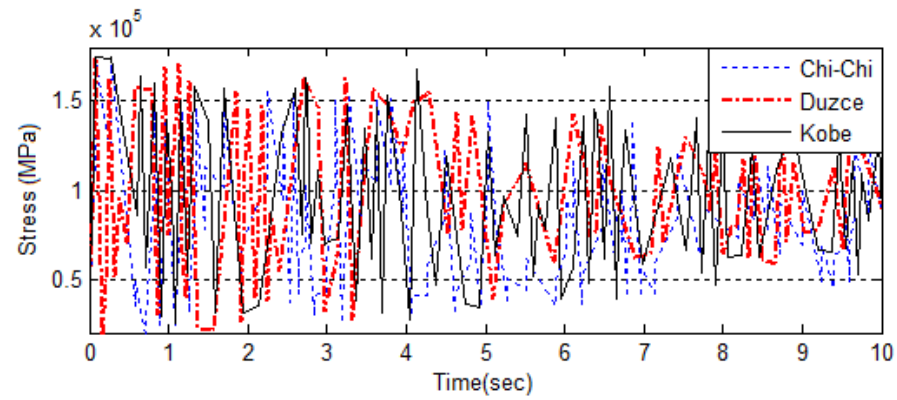

Fig. 15. Stress-time curves for the hybrid tower under the different earthquake loads

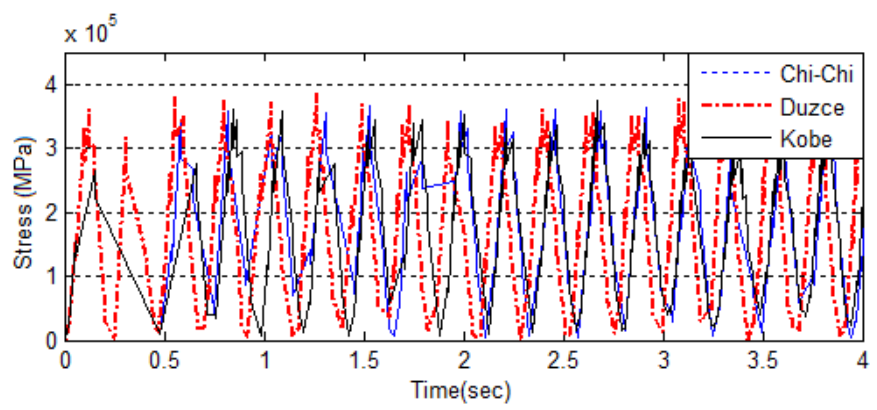

Fig. 16. Stress-time curves for the steel tower under the different earthquake loads

\section{Conclusions}

In this study, 3D model was used to simulate the behavior of wind turbine under static and dynamic loads. Maximum tower tip displacements were used to compare the relative structural performance of various towers. It was observed that the level of varying dynamic forces had a significant effect on the magnitude of the maximum end displacements. In all cases, the largest displacements occurred in the less rigid steel tower type. However, there was no significant displacement difference in different tower types. This is due to the fact that tower heights are low. With the application of the earthquake force, it was observed that the greatest increase in stress occurred in the reinforced concrete tower with the greatest weight. The reason for this is that the earthquake shear force increased proportionally with the weight of structure. At the same time in order to better understand the behavior of the wind turbine, a mathematical model has been defined under static and dynamic loads for the wind turbine.

Based on the results from ABAQUS analysis, it was found that all of the tower types show a reasonable performance under the loads given in Tables 1 and 2. It was not detected any damage in all types tower.

In this study, the maximum earthquake displacements were found as $0.669 \mathrm{~m}, 0.421 \mathrm{~m}$ and 
$0.357 \mathrm{~m}$ for Chi-Chi, Düzce and Kobe earthquakes respectively.

Dynamic analysis of structure under complex loads such as wind load and earthquake forces were taken into account to find out dynamic characteristics of the structure and get optimization of tower type.

Steel wind turbine towers have been the most common solution ever used in the wind industry. The results in this article show that hybrid tower and reinforced concrete towers can provide a suitable alternative and offer improved performance.

\section{Declaration of conflicting interests}

The author(s) declared no potential conflicts of interest with respect to the research. authorship. and/or publication of this article.

\section{References}

[1] Dyrbye C, Hansen SO. Wind Loads on Structures. John Wiley \& Sons, England, 1997.

[2] Krogh T (2004) HAWC load simulation of generic $5 \mathrm{MW}$ offshore wind turbine model. Technical Report. Riso National Laboratory, Roskilde.

[3] Leylek EI. Structural Dynamics: Earthquake Resisting Buildings. Çağlayan Publishing, Istanbul, 2005 (in Turkish).

[4] Norsok Standart. N-004: Design of Steel Structures, Rev. 2, Norway, 2004.

[5] Celep Z, Kumbasar N. Structural Dynamics ( $3^{\text {rd }}$ edition). Rehber Publishing, Istanbul, 2001 (in Turkish).

[6] Clough RW, Penzien J. Dynamics of Structures ( $2^{\text {nd }}$ edition). Mc Graw-Hill, Inc., Singapore, 1993.

[7] Yang H, Zhu Y, Lu Q, Zhang J (2015) Dynamic reliability-based design optimization of the tripod sub-structure of offshore wind turbines. Renewable Energy 78: 16-25.

[8] Patil A, Jung S, Kwon OS (2016) Structural performance of a parked wind turbine tower subjected to strong ground motions. Engineering Structures 120: 92-102.

[9] Quilligan A, O'Connor A, Pakrashi V (2012) Fragility analysis of steel and concrete wind turbine towers. Engineering Structures 36: 270-282.
[10] Hsu Y, Wu WF, Chang YC (2014) Reliability analysis of wind turbine towers. Procedia Engineering 79: 218-224.

[11] Moan T. Recent developments of analysis and design of floating wind turbines. The International Conference on Wind Energy Harvesting, 20-21 April 2017, Coimbra, Portugal.

[12] Negm HM, Maalawi KY (1999) Structural design optimization of wind turbine towers. Computers and Structures 74:649-666.

[13] Lewin TJ. An investigation of design alternatives for 328-ft (100-m) tall wind turbine towers, MSc Thesis, Iowa State University, 2010.

[14] Kanbur FA. Steel tower design for a 500KW wind turbine. MSc Thesis, Istanbul Technical University, 2014.

[15] Manwel JF, McGowan JG, Rogers AL. Wind Energy Explained Theory. Design and Application ( $2^{\text {nd }}$ edition). John Wiley \& Sons Ltd. UK, 2009.

[16] Harte R, Gideon PAG, Zijl V (2007) Structural stability of concrete wind turbines and solar chimney towers exposed to dynamic wind action. Journal of Wind Engineering and Industrial Aerodynamics 95: 1079-1096.

[17] Simulia ABAQUS FEA (2013) Dassault Systems. Velizy-Villacoublay, France.

[18] Tedesco JW, McDougal WG, Ross CA. Structural Dynamics. Addison Wesley Longman Inc., California, USA, 1999.

[19] Huber MT (1904) Czasopismo Techniczne, Lemberg, Austria 22:181.

[20] Carcione JM, Polatto F (2000) Sound velocity of drilling mud saturated with reservoir gas. Geophysics 65: 646-651.

[21] Kocer FY, Arora JS (1996) Design of prestressed concrete transmission poles: Optimization approach. Journal of Structural Engineering 122: 804-814.

[22] Kocer FY, Arora JS (1999) Optimal design of hframe transmission poles for earthquake loading. Journal of Structural Engineering 125: 1299-1308.

[23] Ozdemir A, Sermet F, Yigit ME, Arisoy B, Ercan E. Static analysis of different type of wind turbine towers. The International Conference on Wind Energy Harvesting, 20-21 April 2017, Coimbra, Portugal.

[24] Yigit ME, Ozdemir A, Sermet F, Pinarlik M. Analysis of offshore wind turbine towers with different designs by finite elements method. $9^{\text {th }}$ International Conference on Engineering, 
Technology, Management and Science 2018 (ICETMS 2018), 1-2 July 2018, Barcelona, Spain.

[25] Gökkuş Ü, Yiğit ME, Gücüyen E (2017) Flexible body dynamics of offshore wind turbine under extreme loading conditions. International Journal of Sciences \& Applied Research 4(2): 22-29.

[26] Yiğit ME, Gücüyen E, Gökkuş Ü. Dynamic analysis of offshore wind turbine under linear wave effect according to steel-column-single-degree-offreedom system. In Proceedings of $3^{\text {rd }}$ National
Steel Structures Symposium, 09-12 October 2019, Gaziantep, Turkey, pp. 265-276 (in Turkish).

[27] TIA/EIA-222-F (2013) Structural standards for steel antenna towers and supporting structures.

[28] EWEA Offshore (2013). European Wind Energy Association. Frankfurt, Germany.

[29] Fahjan YM (2008) Selection and scaling of real earthquake accelerograms to fit the Turkish design. IMO Technical Journal 292: 4423-4444 